\title{
Efeito do enxerto ósseo corticoesponjoso na osteogênese em falha cortical ulnar de galinhas domésticas (Gallus domesticus)
}

\author{
[Effect of cortico-cancellous bone grafting in osteogenisis of cortical ulnar failure of \\ domestic chickens (Gallus domesticus)] \\ D.A. Balthazar ${ }^{1}$, M.F.A. Silva ${ }^{2}$, D.S. Castro ${ }^{3}$, S.M.C. Suzano ${ }^{4}$, R.A. Cruz ${ }^{4}$, P.O. Scherer ${ }^{2}$ \\ ${ }^{1}$ Aluno de pós-graduação - Universidade Federal Rural do Rio de Janeiro - Médico veterinário da Fundação \\ RIOZOO - Rio de Janeiro, RJ \\ ${ }^{2}$ Universidade Federal Rural do Rio de Janeiro (UFRRJ) - Seropédica, RJ \\ ${ }^{3}$ Aluno de pós-graduação - Universidade Federal Fluminense (UFF) - Niterói, RJ \\ ${ }^{4}$ Universidade Castelo Branco (UCB) - Rio de Janeiro, RJ
}

\section{RESUMO}

O objetivo do estudo foi avaliar o efeito do enxerto ósseo corticoesponjoso na osteogênese em falha cortical ulnar de galinhas domésticas. Foram utilizadas 18 galinhas, com aproximadamente 70 semanas de idade e peso corpóreo médio de $2,5 \mathrm{~kg}$. Criou-se uma falha óssea na porção diafisária média da ulna em ambas as asas, sendo a direita utilizada como grupo-controle (grupo I) e a esquerda como grupo-tratado (grupo II). As aves foram subdivididas aleatoriamente em quatro subgrupos de acordo com o período de observação (14, 35, 60 e 90 dias). No grupo II, dois fragmentos ósseos da carena do esterno foram retirados, seccionados e implantados na falha óssea. Ao término do período de observação de cada subgrupo, as aves foram abatidas com tiopental sódico para realização dos exames histopatológico e radiográfico post-mortem, com classificação dos resultados em escala semiquantitativa (escore). O grupo II demonstrou osteogênese mais evidente aos 35 e 90 dias de pós-cirúrgico $(\mathrm{P}<0,05)$. Ao comparar os grupos I e II, sem levar-se em consideração o tempo de observação, foi possível observar que houve diferença estatística significativa $(P<0,05)$. Conclui-se que $o$ enxerto ósseo corticoesponjoso demonstra potencial osteogênico satisfatório na espécie estudada, entretanto retarda o tempo de remodelação óssea quando aplicado sobre falhas estáveis pequenas.

Palavras-chave: galinha, falha óssea, enxerto, osteogênese

\begin{abstract}
The aim of this survey was to evaluate the effect of cortico-cancellous bone grafting in osteogenesis in cortical ulnar failure in domestic chickens. Eighteen chickens weighing $2.5 \mathrm{~kg}$ with approximately 70 weeks of age were used. A bone defect in the middle portion of the ulna shaft was created in both wings; the right wing in the control group (Group I) and the left in the treated group (Group II). The birds were randomly divided into four subgroups according to the observation period (14, 35, 60 and 90 days). In group II, two bone fragments of the keel of the sternum were removed, sectioned and implanted in the bone defects. At the end of the observation period for each subgroup, the birds were euthanaized with sodium thiopental to perform the histopathological and radiographic postmortem, with ranking of results in a semi-quantitative scale (score). Group II showed a more evident osteogenisis at 35 and 90 days after surgery $(P<0.05)$. In comparing both groups, without time observation, there was statistical difference $(P<0.05)$. In conclusion, the cortico-cancellous bone graft demonstrated satisfactory osteogenic potential in the specie studied, however, it delays the bone remodeling time when applied in stable small failures.
\end{abstract}

Keywords: chickens, bone defects, graft, osteogenisis

\section{INTRODUÇÃO}

Na clínica aviária, uma grande proporção dos problemas tem resolução cirúrgica e, dentre as cirurgias, as fraturas de ossos longos estão entre as mais comuns (Leotte et al., 2004). As falhas ósseas constituem grande desafio ao cirurgião e são comuns na cirurgia ortopédica aviária (Bolson et al., 2005). Uma das principais opções para preenchimento de falhas ósseas provocadas

Recebido em 29 de março de 2012

Aceito em 8 de outubro de 2012

E-mail: danielbalthazar@yahoo.com.br 
por fraturas cominutivas de ossos longos é a substituição de um segmento ou o preenchimento da falha utilizando-se enxerto ou implante como adjuvantes no tratamento (Henry e Wadsworth, 1981; Santos e Rahal, 2004).

O enxerto de osso esponjoso autólogo apresenta vantagens sobre outros tipos de enxertos ou implantes, por possuir, além de propriedades osteocondutoras, elevado potencial osteogênico e osteoindutivo. Esse tipo de enxerto ósseo possui também as vantagens de histocompatibilidade e ausência de risco de transmissão de doenças infectocontagiosas (Dias et al., 2007). A ausência de propriedades mecânicas é compensada pela grande capacidade osteogênica, responsável por rápida neoformação de tecido ósseo no local da fratura, o que irá contribuir para rápida estabilização (Stevenson, 1998).

O objetivo do presente estudo foi avaliar o efeito do enxerto ósseo corticoesponjoso na osteogênese em falha cortical ulnar de galinhas domésticas (Gallus domesticus), mediante acompanhamento radiológico e histopatológico da cicatrização óssea.

\section{MATERIAL E MÉTODOS}

Foram utilizadas 18 galinhas domésticas (Gallus domesticus), fêmeas, com idade aproximada de 70 semanas e peso corporal médio de $2,5 \mathrm{~kg}$. Para efeitos de redução no número de animais utilizados e supressão das variações individuais, estes foram submetidos ao processo cirúrgico em ambas as asas. A asa direita foi utilizada como controle (grupo I), na qual foi criada falha óssea na face lateral da ulna; na asa esquerda o mesmo procedimento foi realizado e a falha foi preenchida com enxerto ósseo corticoesponjoso retirado da carena do esterno (grupo II) (Fig. 1). Os grupos controle (grupo I) e tratado (grupo II) foram subdivididos aleatoriamente em quatro subgrupos cada, de acordo com o período de observação (14, 35, 60 e 90 dias).

Como medicação pré-anestésica, foi utilizada uma dose de $2 \mathrm{mg} . \mathrm{kg}^{-1}$ de butorfanol, associado a 20mg. $\mathrm{kg}^{-1}$ de cetamina e $1 \mathrm{mg} . \mathrm{kg}^{-1}$ de midazolam, todos administrados simultaneamente, pela via intramuscular, no músculo peitoral. A manutenção anestésica foi realizada com isoflurano ao efeito.
Como terapia antimicrobiana profilática, foi aplicada, por via intramuscular, gentamicina, na dose de $5 \mathrm{mg} . \mathrm{kg}^{-1}$, associada a enrofloxacina, na dose de $15 \mathrm{mg} \cdot \mathrm{kg}^{-1}$.

Após acesso cirúrgico à superfície lateral da ulna, foi criada uma falha óssea com aproximadamente $3,3 \mathrm{~mm}$ de largura e $1,6 \mathrm{~mm}$ de profundidade com auxílio de uma broca fresa $1 / 8$ ", com 3,2mm de diâmetro e corte lateral, a qual foi acoplada à microrretífica com eixo flexível, na velocidade de 5.000 rotações por minuto. A incisão foi imediatamente suturada em plano único, aproximando subcutâneo e pele com fio de nylon (3-0), no padrão de pontos simples isolados.

O mesmo procedimento foi realizado na asa esquerda até a produção da falha, quando, então, a pele foi aproximada temporariamente com uma pinça Backhaus de $13 \mathrm{~cm}$, e a asa envolvida com compressa cirúrgica estéril para posicionamento do animal em decúbito dorsal.

Para retirada do tecido ósseo corticoesponjoso, a carena do esterno foi acessada, e com auxílio de uma cizalha Luer goiva simples reta, foram retirados dois fragmentos do processo ósseo. Estes foram imediatamente seccionados com lâmina de bisturi, gerando aproximadamente 18 pedaços medindo em torno de $3 \mathrm{~mm}$, colocados, então, em gaze estéril embebida com solução de cloreto de sódio $0,9 \%$, até serem implantados na falha óssea já criada na ulna esquerda. Os planos muscular e subcutâneo foram aproximados com fio poligalactina 910 (3-0) em padrão de sutura simples contínua, e a pele da região esternal fechada com fio de nylon (3-0) em pontos simples isolados.

$\mathrm{O}$ animal foi reposicionado em decúbito esternal para que a falha óssea da asa esquerda fosse acessada. Os fragmentos foram aplicados sobre a falha óssea, levemente comprimidos, e o tecido celular subcutâneo e a pele imediatamente suturados em plano único com fio de nylon (3-0), no padrão de pontos simples isolados.

No pós-operatório, foram administrados meloxicam, na dose de $0,2 \mathrm{mg} \cdot \mathrm{Kg}^{-1}$, SID, durante três dias, pela via subcutânea, e gentamicina, na dose de $5 \mathrm{mg} . \mathrm{kg}^{-1}$, SID, associada à enrofloxacina, na dose de $15 \mathrm{mg} . \mathrm{kg}^{-1}$, SID, 
durante 10 dias, ambas administradas pela via intramuscular.

Ao término do período de observação $(14,35,60$ e 90 dias), os animais foram abatidos com tiopental sódico, intravenoso, na dose de $40 \mathrm{mg} \cdot \mathrm{kg}^{-1}$, coletando-se, então, fragmentos das ulnas direita e esquerda para realização do exame histopatológico e radiográfico post-mortem das lesões.

Os fragmentos de epífise ulnar com a lesão localizada centralmente foram descarnados, fixados em formol a $10 \%$ e radiografados sob regime elétrico de $55 \mathrm{kV}$ e $5 \mathrm{~mA}$, simulando a projeção dorsoventral. Foi avaliada a proliferação tecidual nas proximidades da falha óssea.

Após procedimentos radiográficos os fragmentos foram descalcificados em solução de ácido nítrico a $10 \%$, clivados transversalmente e processados pela técnica de inclusão em parafina. Foram confeccionados cortes histológicos de aproximadamente $4 \mu \mathrm{m}$ as lâminas processadas foram coradas com hematoxilina-eosina (HE), para posterior avaliação do processo de reparação em microscópio óptico com aumento de 40x e 100x. Com o objetivo de avaliar a reparação da falha óssea e o potencial osteogênico do enxerto ósseo implantado, nessa análise foram consideradas:

- a evolução do processo de reparação da falha, sendo observada a reação inicial do periósteo e, principalmente, a maturação do tecido ósseo neoformado que preenchia a área entre as duas corticais (falha óssea);

- a quantidade total de tecido ósseo neoformado.

Para análise dos resultados expressos em escores (Tab. 1) - grau de proliferação tecidual nas proximidades da falha óssea visível radiograficamente; reação inicial do periósteo e maturação do tecido ósseo neoformado que preenchia a área entre as duas corticais; e a quantidade total de tecido ósseo neoformado -, foi utilizado teste de Wilcoxon para comparação entre grupos em cada momento, assim como para comparação dos grupos considerando-se todos os momentos. Os resultados foram considerados a partir do nível de 5\% de significância.

Tabela 1. Galinha: escala semiquantitativa para avaliação do grau de proliferação tecidual nas proximidades da falha óssea, com visibilização radiográfica (A), da reação inicial do periósteo e maturação do tecido ósseo neoformado que preenchia a área entre as duas corticais (falha óssea) (B), e para avaliação da quantidade total de tecido ósseo neoformado (C)

\begin{tabular}{lc}
\hline A. Proliferação tecidual nas proximidades da falha óssea & Escore (pontos) \\
\hline Ausência de proliferação óssea & 1 \\
Proliferação óssea leve & 2 \\
Proliferação óssea moderada & 3 \\
Proliferação óssea intensa & Escore (pontos) \\
\hline B - Reação periosteal e maturação do tecido ósseo neoformado & 0 \\
\hline Ausência de reação periosteal & 1 \\
Resposta periosteal moderada & 2 \\
Resposta periosteal intensa & 3 \\
Tecido ósseo neoformado desorganizado & 4 \\
Tecido ósseo neo formado em moderada organização & 5 \\
Tecido ósseo neo formado em avançada organização & Escore (pontos) \\
\hline C - Quantidade de tecido ósseo neoformado & 0 \\
\hline Ausência de neoformação óssea & 1 \\
Neoformação óssea discreta & 2 \\
Neoformação óssea discreta/moderada & 3 \\
Neoformação óssea moderada & 4 \\
Neoformação óssea moderada/intensa & 5 \\
Neoformação óssea intensa & \\
\hline
\end{tabular}




\section{RESULTADOS}

Os animais do subgrupo Ia (14 dias de pósoperatório) apresentaram ausência de imagens radiográficas compatíveis com proliferação óssea. No exame histopatológico, em três dos quatro animais avaliados houve reação periosteal moderada e uma quantidade de tecido ósseo neoformado discreta. Somente um dos animais estudados nesse subgrupo mostrou reação periosteal intensa e uma quantidade de tecido ósseo neoformado discreta/moderada. Nos animais do subgrupo IIa, com mesmo tempo de observação, mas com implantação de enxerto ósseo, não foi possível a observação de imagens radiográficas compatíveis com a presença de fragmentos do enxerto ou proliferação óssea, entretanto todos mostraram reação periosteal intensa e uma quantidade de tecido ósseo neoformado discreta/moderada na histopatologia. Em todos os animais desse subgrupo foram observados fragmentos de enxerto ósseo distribuídos próximos à falha cortical, envoltos por tecido fibroso desorganizado e com presença de neovascularização.

Nos animais do subgrupo Ib (35 dias de pósoperatório), não foi possível a observação de imagens radiográficas compatíveis com proliferação óssea. Em dois dos quatro animais avaliados houve a formação de tecido ósseo moderadamente organizado na falha encontrada entre as duas corticais, e uma quantidade de tecido ósseo neoformado variando de discreta a discreta/moderada. Nos outros dois animais desse subgrupo, foi possível observar a formação de tecido ósseo desorganizado na falha óssea, e uma quantidade de tecido ósseo neoformado de discreta a discreta/moderada. No subgrupo IIb, foi possível a observação de imagens radiográficas compatíveis com proliferação óssea intensa em dois dos quatro animais estudados, entretanto, no animal 15, essa imagem encontrava-se formada fora do local da falha. Os outros dois animais desse subgrupo apresentaram imagens radiográficas compatíveis com leve proliferação óssea. Durante a avaliação histológica, foi possível observar a formação de tecido ósseo variando de desorganizado a moderadamente organizado, e quantidade moderada de tecido ósseo neoformado. Vale ressaltar que, no animal 15, essa neoformação ocorreu fora da área da lesão e o tecido ósseo neoformado que preenchia a área da falha era oriundo do endósteo, encontrando-se em um grau moderado de organização.

Os animais do subgrupo Ic (60 dias de pós-cirúrgico) não demonstraram imagens radiográficas compatíveis com proliferação óssea. Nos quatro animais avaliados houve a formação de tecido ósseo moderadamente organizado na falha, entretanto o animal 5 não apresentou a formação de uma ponte unindo as duas corticais, notando-se a presença de tecido fibroso adentrando a medular. A quantidade de tecido ósseo neoformado variou de discreta a moderada. No subgrupo IIc, dois animais apresentaram imagens radiográficas compatíveis com proliferação óssea intensa, enquanto os animais 16 e 17 apresentaram ausência ou proliferação óssea leve, respectivamente. A avaliação histológica demonstrou tecido ósseo no local da falha variando de desorganizado a moderadamente organizado, e a quantidade de tecido ósseo neoformado mostrou grande variabilidade de resultados, indo de discreta a moderada/intensa.

No subgrupo Id (90 dias após a cirurgia), quatro dos seis animais não apresentaram reações de proliferação óssea radiologicamente visíveis, os animais 7 e 10 apresentaram discreta e moderada proliferação óssea, respectivamente. Com relação à avaliação histológica, três dos seis animais já apresentavam estágios avançados de remodelação óssea na ponte formada entre as duas corticais, e os demais animais apresentaram-se em estágios variando do tecido ósseo desorganizado ao moderadamente organizado. Cinco dos animais estudados apresentaram neoformação de tecido ósseo discreta/moderada, enquanto um dos animais apresentou uma neoformação moderada. Todos os animais do subgrupo IId mostraram algum grau de proliferação óssea no exame radiográfico, variando este de uma leve a intensa resposta proliferativa. Nenhum dos animais no subgrupo IId alcançou graus avançados de organização tecidual na falha, seus escores variaram de 3 a 4 , demonstrando a presença de tecido ósseo neoformado ainda desorganizado ou moderadamente organizado. Entretanto, a quantidade de tecido ósseo neoformado variou de moderada a intensa.

A Tab. 2 demonstra os resultados da avaliação semiquantitativa acima descritos, realizada nos 
animais em diferentes períodos, com ou sem a presença de enxerto ósseo corticoesponjoso.

Comparando-se os diferentes tratamentos, nos diferentes tempos, foi possível observar que houve diferença estatística significativa $(\mathrm{P}<0,05)$ entre os grupos controle e tratado aos 14, 35 e 90 dias de pós-cirúrgico. Ou seja, o grupo-tratado mostrou um potencial osteogênico maior que o grupo-controle, mesmo quando se considerou importante a variável organização do tecido ósseo neoformado na falha entre as duas corticais, entretanto, nos momentos 60 dias, não foram observadas diferenças estatísticas significativas. Quando foram comparados os 18 animais dos grupos controle e tratado sem levarse em consideração o tempo de observação, foi possível observar que houve diferença estatística significativa $(\mathrm{P}<0,05)$ entre os dois grupos.

Tabela 2. Galinha: resultados expressos em escores do grau de proliferação tecidual nas proximidades da falha ulnar experimentalmente produzida ao exame radiográfico (PT); reação inicial do periósteo e maturação do tecido ósseo neoformado que preenchia a área entre as duas corticais (FO); e quantidade total de tecido ósseo neoformado (TN), soma da pontuação de cada animal $\left(\sum\right)$, média desta soma $(\overline{\mathrm{x}})$, desvio-padrão $(S D)$ e valor de $\mathrm{P}(<0,05)$

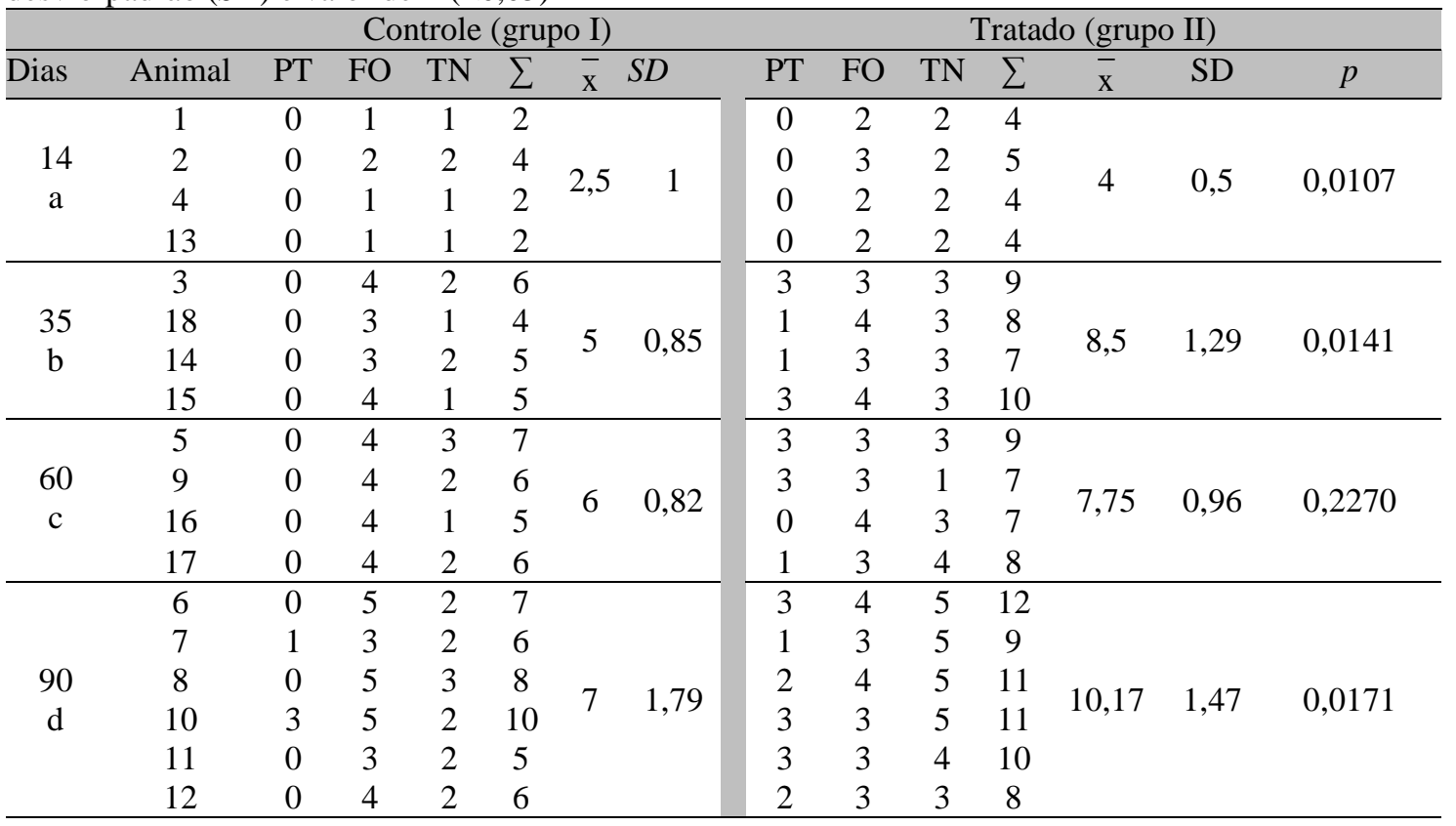

\section{DISCUSSÃO}

Optou-se pela colheita de osso corticoesponjoso na carena do esterno, pois Bennet (1997) cita que é o local de escolha quando se necessita de grande quantidade de tecido ósseo. Imediatamente após a colheita, os fragmentos foram cortados, permanecendo com cerca de $3 \mathrm{~mm}$. Isso porque Santos e Rahal (2004) recomendam que os fragmentos enxertados não devem possuir menos que $0,7 \mathrm{~mm}$, pois não estimulariam a osteogênese, concordando com Weigel (1996), que cita a importância do tamanho da partícula óssea na vascularização e sobrevivência das células do enxerto.
Durante a aplicação do enxerto no local receptor, foi realizada uma leve compressão, visto que Martinez et al. (1992), em trabalho utilizando cães, não detectaram diferenças na capacidade osteogênica entre os enxertos aplicados com ou sem compressão.

Del Carlo et al. (2004), em experimento utilizando polímero de mamona acrescido de cálcio, associado ou não com medula óssea em falhas criadas no rádio de coelhos, relataram que, aos 21dias de observação, o polímero implantado na falha apresentou-se envolto por uma camada de tecido fibroso, assim como observado no presente estudo aos 14 dias de observação. Vale ressaltar que, aos 35 dias, esse tecido conjuntivo 
já se apresentava organizado e, assim como observado por Ignácio (1995), ele vai sendo gradativamente substituído por tecido ósseo imaturo.

As propriedades osteocondutoras do enxerto foram observadas nos animais que foram avaliados aos 14 dias de pós-cirúrgico, quando havia neovascularização no interior das trabéculas ósseas dos fragmentos enxertados. Essa propriedade é conferida pela estrutura tridimensional, formada por tecido ósseo trabecular, que irá permitir uma rápida revascularização (Dias et al., 2007). Conforme relatado por Einhorn (1995), as fraturas estáveis promovem um aumento da sobrevivência de células do enxerto devido a essa rápida revascularização, permitindo um bom contato entre o leito receptor e o enxerto. Mediante os resultados aqui apresentados, pode-se considerar que a estabilidade no foco favoreceu a manutenção de células vivas no enxerto, o que explica a atividade proliferativa intensa no grupo-tratado desde a primeira fase de avaliação.

$\mathrm{Na}$ avaliação histológica aos 14 dias de póscirúrgico, foi observada maior reação periosteal nos animais tratados quando comparados aos do grupo-controle, o que pode ser explicado pelas propriedades osteoindutivas do enxerto que promovem quimiotaxia, mitose e diferenciação de células mesenquimatosas pluripotenciais em células das linhas condrogênica e osteogênica. As células inflamatórias atraídas para o sítio da lesão secretam mediadores químicos, presentes nos três primeiros dias pós-lesão, sendo determinantes na regulação dos eventos iniciais, constituindo reguladores importantes de proliferação e diferenciação celulares (Junqueira e Carneiro, 1999; Dias et al., 2007).

O enxerto ósseo corticoesponjoso utilizado no presente estudo demonstrou um potencial osteogênico satisfatório, visto que, durante a avaliação, o grupo II, composto por falhas ósseas que receberam o implante de fragmentos de enxerto, demonstrou maior produção de osso neoformado em comparação ao grupo-controle (Fig. 2). Esse potencial osteogênico tem origem na extensa área de superfície coberta por células de revestimento do tecido ósseo transplantado em associação com células da medula óssea. A atividade osteogênica máxima foi alcançada após 60 dias de observação, o que concorda com Stevenson (1999), que relata uma atividade osteogênica iniciada por volta do quinto dia após implantação e atividade máxima a partir da oitava semana após o transplante.

No presente trabalho, o modelo experimental desenvolvido apresentava-se como uma fratura estável, uma vez que a solução de continuidade não envolvia todo o diâmetro do osso. Isto pôde ser comprovado no grupo-controle pela formação de calo entre as extremidades da falha, principalmente a partir do endósteo, com estágio bastante avançado de remodelação óssea aos 90 dias, sem formação de calos externos. Piermatei e Flo (1999) afirmam que a consolidação em lacunas pequenas e muito estáveis é reparada transpassando a maioria dos estágios de uma cicatrização óssea indireta, indo logo ao remodelamento ósseo. Assim, a quantidade de calo ósseo externo presente é inversamente proporcional ao processo de remodelação, situação esta observada no grupo-tratado aos 90 dias de observação. Nesse momento, nenhum dos animais avaliados apresentou organização intensa do tecido ósseo que recobria a interface entre as duas corticais, mostrando que, assim como relatado por Stevenson (1999), esse processo de organização lamelar do calo externo pode ter duração de vários meses, ocorrendo a substituição do tecido ósseo não lamelar recémformado por tecido ósseo lamelar, constituído por sistemas de Havers.

Mesmo sabendo que o enxerto induziu a um retardo na remodelação, sua capacidade osteogênica aqui observada pode representar um ganho no tratamento das fraturas de aves, pois a formação precoce do calo pode conferir estabilidade inicial para manutenção da biomecânica normal, fator de grande importância principalmente nas fraturas dos ossos longos das asas, conforme afirmam Yamazoe et al. (1994). 
Efeito do enxerto ósseo...

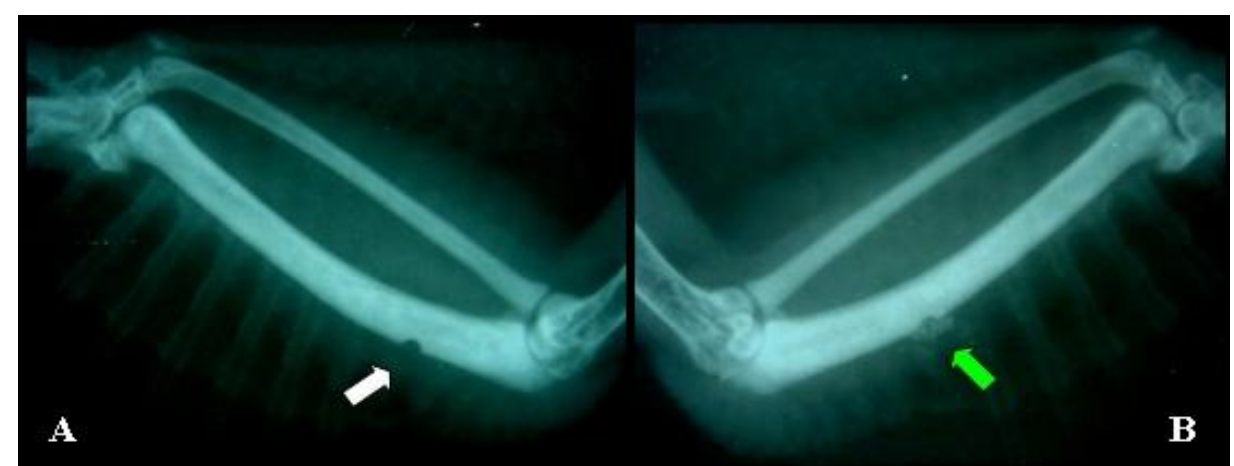

Figura 1. Galinha: (A) Radiografia realizada no pós-operatório imediato na posição dorsoventral da região do antebraço direito (grupo-controle), demonstrando a falha óssea criada na porção lateral da ulna (seta branca). (B) Radiografia realizada no pós-operatório imediato, na posição dorsoventral da região do antebraço esquerdo (grupo-tratado), demonstrando a falha óssea criada na porção lateral da ulna, preenchida com fragmentos de enxerto ósseo corticoesponjoso (seta verde).

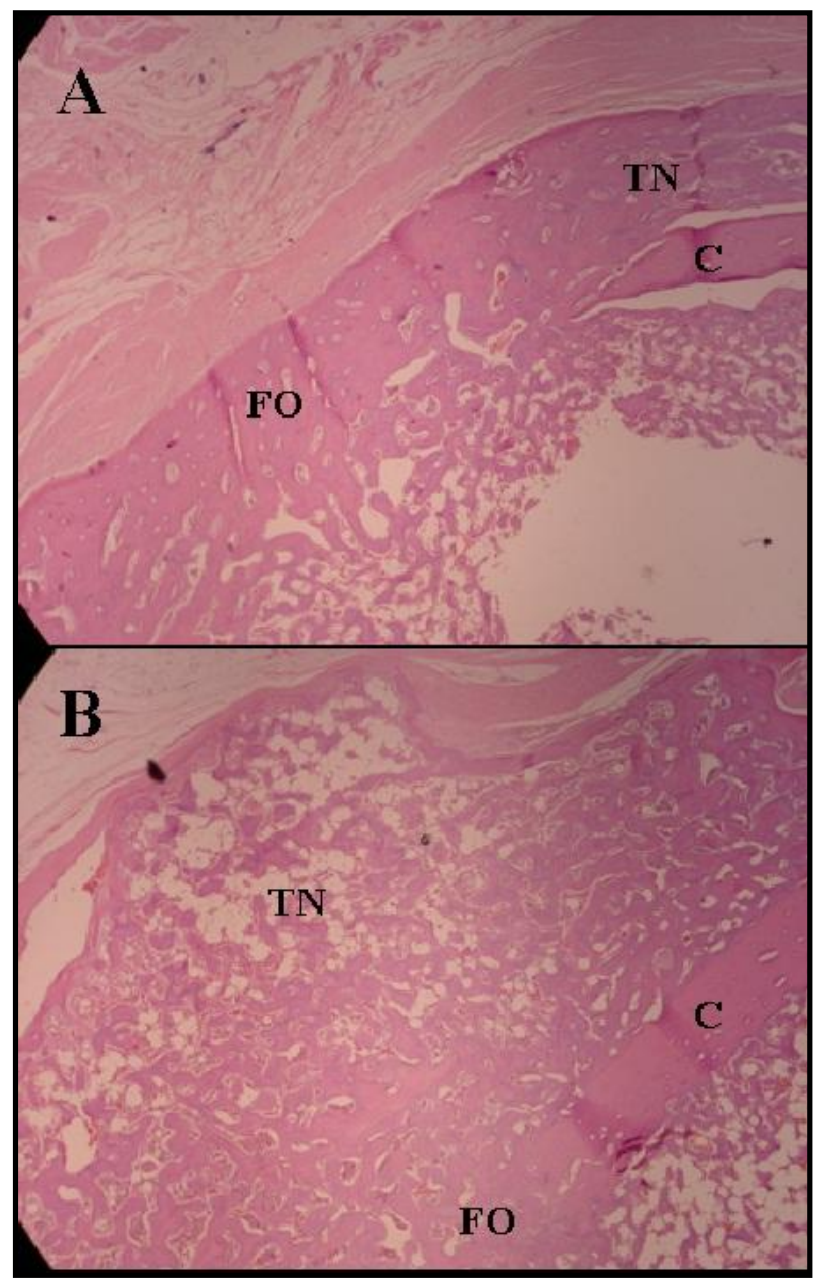

Figura 2. Galinha: fotomicroscopia ulna. Comparação entre grupos controle (A) e tratado (B), aos 90 dias. Osso cortical (C); no grupo-controle (A), pode ser observada uma avançada maturação do tecido ósseo neoformado preenchendo a área entre as duas corticais (FO); no grupo-tratado (B), pode ser observada maior proliferação de tecido ósseo neoformado (TN) que no grupo-controle (HE 40X). 


\section{CONCLUSÃO}

Após análise dos resultados, pôde-se concluir que o enxerto ósseo corticoesponjoso demonstrou potencial osteogênico satisfatório, entretanto retarda o tempo de remodelação óssea quando aplicado sobre falhas estáveis pequenas. Sua aplicação mostrou-se de simples execução, não implicando a adição de custo ao tratamento das fraturas, o que indica forte possibilidade de aplicação na clínica aviária. Avaliações em modelos de fraturas cominutivas instáveis, com perda de esquírolas ósseas, de ocorrência mais comum nessas espécies, poderão dar suporte para sua utilização como rotina na ortopedia aviária.

\section{REFERÊNCIA}

BENNETT, R.A. Orthopedic surgery. In: ALTMAN, R.B.; CLUBB, S.L.; DERROSTEIN, G.M.; QUESENBERRY, K. Avian Medicine and Surgery. 1.ed. Philadelphia: Saunders, 1997. Cap.42, p.733 - 766.

BOLSON, J. Comportamento do plímero de mamona (Ricinnus communis) em ossos de codornas domésticas (Coturnix japônica). 2005. 57f. Dissertação (Mestrado em cirurgia) Programa de Pós-graduação em Medicina Veterinária, Universidade Federal de Santa Maria, Santa Maria.

DEL CARLO, R.J.; KAWATA, D.; VILORIA, M.I.V. et al. Polímero derivado de mamona acrescido de cálcio, associado ou não à medula óssea autógena na reparação de falhas ósseas. Cienc. Rural, v.33, p.1081-1088, 2004.

DIAS, M.I.; LOURENÇO, P.; RODRIGUES, A. et al. Efeitos da quantidade do enxerto de osso esponjoso autólogo utilizado na regeneração óssea num modelo experimental de osteotomia de tíbia. Acta Med. Portuguesa, v.20, p.37-46, 2007.

EINHORN, T.A. Current concepts review enhancement of fracture-healing. J. Bone Joint Surg., v.77-A, p.940-956, 1995.

HENRY, W.B.; WADSWORTH, P.L. Diaphyseal allografts in the repair of long bones fractures. J. Am. Anim. Hosp. Associat., v.17, p.525-534, 1981 .
IGNÁCIO, H. Utilização do cimento derivado do polímero da mamona no preenchimento de falha óssea. Estudo experimental em coelhos. 1995. 96f. Dissertação (Mestrado em ortopedia e traumatologia) - Faculdade de Medicina, Universidade de São Paulo, São Paulo.

JUNQUEIRA, J.C.; CARNEIRO, J. Histologia básica. 9.ed. Rio de Janeiro: Guanabara Koogan, 1999. 427p.

LEOTTE, A.M.; RAISER, A.G.; BRAGA, F.A. et al. Fixação esquelética externa tipo Ia (unilateral-uniplanar) para osteossíntese diafisária de úmero em pombos domésticos (Columba livia). Cienc. Rural, v.34, p.18651870, 2004.

MARTINEZ, S.A.; PROBST, C.W; HAUPTMAN, J.G. et al. Effects of a fixed compression load on the osteogenic effect of autogenous cancellous bone grafts in dogs. Am. J. Vet. Res., v.53, p.2381-2385, 1992.

PIERMATTEI, D.L.; FLO, G.L. Manual de Ortopedia e Tratamento de Fraturas dos Pequenos Animais. 3.ed. São Paulo: Manole, 1999. 694p.

SANTOS, F.C.; RAHAL, S.C. Enxerto ósseo esponjoso em pequenos animais. Cienc. Rural, v.34, p.1969-1975, 2004.

STEVENSON, S. Enxertos ósseos. In: SLATTER, D. Manual de Cirurgia de Pequenos Animais. 2. ed. São Paulo: Manole, 1998. v.2, cap.127, p.2006, 2017

STEVENSON, S. Biology of bone grafts. Orthop. Clin. North Am., v.30, p.543-552, 1999.

WEIGEL, J.P. Enxerto ósseo. In: BOJRAB, M.J.; SMEAK, D.D.; BLOOMBERG, M.S. Mecanismos da Moléstia na Cirurgia de Pequenos Animais. 2.ed. São Paulo: Manole, 1996. Cap.98, p.791-798.

YAMAZOE, K.; HIBINO, C.; KUDO, T. et al. The reduction of humeral fracture in pigeons with intramedullary poly (methylmethacrylate) and neutralization plate fixation. J. Vet. Med. Sci., v.56, p.739-745, 1994. 